\title{
An Empirical Research on the Relationship of the Palm Oil Futures Prices between China and Malaysia
}

\author{
Jing Lou \\ School of Economics \\ Shanghai University \\ Shanghai, China \\ e-mail: zhuizj6j@sina.com
}

\begin{abstract}
Malaysia is a major producer and exporter of palm oil in the word while China is a major importer and consumer. In order to study the relationship of the palm oil futuers prices between Buras Malaysia Derivatives (BMD) and Dalian Commodity Exchange (DCE), this article used a series methods such as correlation coefficient, Augmented Dickey-Fuller and Johansesn Cointegration Tests, Granger Causality Tests, Variance Decomposition and Impulse Response Function. The results show that there are longterm cointegration relation and strong correlation on palm oil futuers prices between BMD and DCE. Moreover, the palm oil futuers price of BMD lead that of DCE, but the palm oil futures price of DCE do not lead that of BMD. This study further validates Malaysia has the status of world palm oil fixing prices center. It also suggests that intertemporal arbitrage and cross matket arbitrage opportunities are exist in BMD and DCE palm oil futures markets.
\end{abstract}

Keywords-Palm oil futures price; Cointegration; Causality Tests; Variance Decomposition; Impulse Response Function

\section{INTRODUCTION}

Palm oil is one of the major vegetable oil in the world. 2013 world palm oil production reached 55.97 million tons. Between 2000 to 2013 , the world's palm oil production rapid growth to $6.5 \%$ average annual growth rate, becoming the world's fastest-growing vegetable production. With the rapid increase in production, there was also a strong growth of palm oil trade. The world's palm oil exports reached 43.42 one million tons in 2013, accounting for $77.58 \%$ of total output ${ }^{1}$.

The rapid development and trade of the world's palm oil production led to the development of the palm oil futures market. In October 2007, palm oil futures listed in Dalian Commodity Exchange (Dalian Commodity Exchange, hereinafter referred to as DCE).Previously, Buras Malaysia Derivatives (Buras Malaysia Derivatives, hereinafter referred to as BMD), Joint Asian Derivatives Exchange (Joint Asian Derivatives Exchange, hereinafter referred to as JADE) and Multi Commodity Exchange of India (Multi Commodity Exchange of India, hereinafter referred to as MCE) lanched palm oil futures trading. Malaysia is the world's major producer and exporter of palm oil, good spot basis has created good conditions for BMD of palm oil futures trading. China is the world's main importer and consuming countries of palm oil. In the nearly six years since palm oil futures has been lanched in DCE, volume and turnover were gradually increasing and DCE palm oil futures market was gradually mature.

Due to fluctuations of one futures market price will be passed to other futures markets, the relationship of influence between the same or similar furutes in different futures market has received lots of attention, mainwhile, cross market arbitrage based on this theory. International and domestic academics performed a large number of studies about the influence relationship between the same or similar furutes in different futures market. Among the studies, agricultural products are mainly focused on soybean, corn, natural rubber and etc. There is no systematic research and discussion on the relationship of the palm oil futures prices between the typical two palm oil futures markets: BMD and DCE. The research on BMD and DCE palm oil futures market price correlation not only has practical significance, but also fill the blank in the related field of research.

\section{EMPIRICAL RESEARCH}

\section{A. Data Sources and Processing}

This artical selects main palm oil continuous contract's daily closing prices of BMD (hereinafter referred to as PRICES_BMD, unit: RMB yuan/ ton) and DCE (hereinafter referred to as PRICES_DCE, unit: Ringgit/ton) as research objects. Due to the holidays are difference between BMD and DCE, in order to keep the sample data pairs, this article deletes data that do not match and then obtains 1154 pairs of data. Among them, DCE's data comes from DCE's website (http://www.dce.com.cn/) while BMD's data comes from Mandarin Financial market software.

\section{B. The Discription of the Relevance of DCE and BMD Palm Oil Futures}

Draw the sample data time series line chart in Excel (see Fig .1). Using R3.1.0 to calculate the two time series' correlation coefficient is 0.957 , which is very close to 1 . The result shows that there is a strong correlation between the two time series of PRICES_BMD and PRICES_DCE. However, the result only shows statistically significant, econometric models are needed to further analyze the dynamic relationship between the two time series.

\footnotetext{
${ }^{1}$ Data sources: Wind Info.
} 


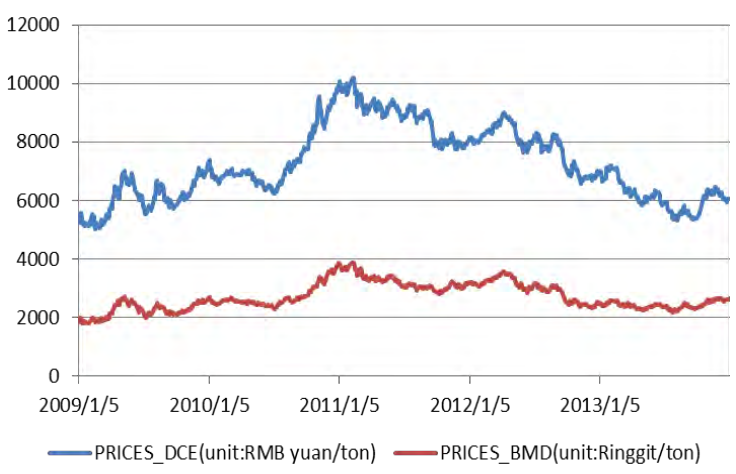

Figure 1. PRICES_DCE and PRICES_BMD time series line chart

\section{Stationarity Test}

The time series stationarity is the foundation of time series analysis, so firstly analyze the stationarity of the time series by the unit root test. This article use the main unit root test method: augmented Dickey-Fuller (ADF) test to test the original time series and the first order difference time series respectively (see TABLE I ).

TABLE I. ADF TEST RESULT

\begin{tabular}{|c|c|c|c|c|c|c|}
\hline variable & $\begin{array}{c}\mathrm{ADF} \\
\text { statistics }\end{array}$ & $\begin{array}{c}1 \% \\
\text { standard } \\
\text { value }\end{array}$ & $\begin{array}{c}5 \% \\
\text { standard } \\
\text { value }\end{array}$ & $\begin{array}{c}10 \% \\
\text { standard } \\
\text { value }\end{array}$ & $\mathrm{p}$-value & $\begin{array}{l}\text { judge } \\
\text { ment }\end{array}$ \\
\hline $\begin{array}{c}\text { PRICES_B } \\
\text { MD }\end{array}$ & 0.2172 & -2.5670 & -1.9411 & -1.6165 & 0.7492 & $\begin{array}{c}\text { not } \\
\text { statio- } \\
\text { nary }\end{array}$ \\
\hline $\begin{array}{c}\text { PRICES_D } \\
\text { CE }\end{array}$ & -0.0597 & -2.5670 & -1.9411 & -1.6165 & 0.6628 & $\begin{array}{c}\text { not } \\
\text { statio- } \\
\text { nary }\end{array}$ \\
\hline $\begin{array}{c}\triangle \text { PRICES } \\
\text { BMD }\end{array}$ & -34.6318 & -2.5670 & -1.9411 & -1.6165 & 0.0000 & $\begin{array}{l}\text { Statio } \\
\text {-nary }\end{array}$ \\
\hline $\begin{array}{l}\triangle \text { PRICES } \\
\text { DCE }\end{array}$ & -34.8906 & -2.5670 & -1.9411 & -1.6165 & 0.0000 & $\begin{array}{l}\text { Statio } \\
\text {-nary }\end{array}$ \\
\hline
\end{tabular}

TABLE I shows that the ADF statistics of PRICES_BMD and PRICES_DCE are both greater than their corresponding $1 \%$ standard value.The $p$ value is 0.7492 and 0.6628 respectively, obliged not to reject the null hypothesis, so the time series are not stationary.

After the first order difference, the ADF statistics of $\triangle$ PRICES_BMD and $\triangle$ PRICES_DCE are both less than their corresponding $1 \%$ standard value. The $\mathrm{p}$ value are both 0.0000 , obliging to reject the null hypothesis, so the time series are stationary. Two time series are all I(1) sequence, and then test the cointegration relationship between the PRICES_BMD and PRICES_DCE.

\section{Johansen Cointegration Test}

Cointegration test is to explore whether there is a long-term synergetic trend between the non-stationary time series, to judge the existence of a long-term equilibrium relationship: cointegration relationship between the nonstationary time series. E-G two-step test that based on regression residual stationarity and Johansen test that based on maximum likelihood estimation are often used to test the cointegration. In the practical research, Johansen test is widely used for it overcoming some disadvantages of the E-G two-strp test, so I choose to use Johansen cointegration test in this article.

Determine the optimizing lag number of the VAR model first because Johansen cointegration test is sensitive to VAR's lag number. Test result of PRICES_BMD and PRICES_DCE unconstrained VAR model's lag number is as follows (see TABLE II). TABLE II shows that the unconstrained VAR model's optimizing lag number is 6 . According to the relationship between Johansen test's optimizing lag number and VAR model's optimizing lag number, Johansen test's optimizing lag number is 5 .

TABLE II. TEST RESULT OF UNCONSTRAINED VAR MODEL'S LAG NUMBER

\begin{tabular}{c|c|c|c|c}
\hline criteria & AIC (n) & HQ(n) & SC(n) & FPE(n) \\
\hline 1 & 16.0876 & 16.0976 & 16.1141 & 9699771.0000 \\
2 & 16.0127 & 16.0293 & 16.0568 & 8999446.0000 \\
3 & 16.0119 & 16.0352 & 16.0736 & 8992220.0000 \\
4 & 16.0135 & 16.0435 & 16.0929 & 9006981.0000 \\
5 & 16.0177 & 16.0543 & 16.1147 & 9044931.0000 \\
6 & 16.0095 & 16.0527 & 16.1241 & 8970696.0000 \\
7 & 16.0130 & 16.0630 & 16.1453 & 9002750.0000 \\
8 & 16.0141 & 16.0707 & 16.1640 & 9012594.0000 \\
9 & 16.0191 & 16.0823 & 16.1865 & 9057106.0000 \\
10 & 16.0225 & 16.0924 & 16.2076 & 9088467.0000 \\
\hline selection & 6 & 2 & 2 & 6 \\
\hline
\end{tabular}

TABLE III shows the Johansen cointegration test result. Trace statistics is greater than critical value of $5 \%$ level under the confidence level of 5\%, so null hypothesis is rejected, showing that there exist a long-term equilibrium cointegration relationship between PRICES_BMD and PRICES_DCE.

TABLE III. JOHANSEN COINTEGRATION TEST RESULT

\begin{tabular}{c|c|c|c|c}
\hline$H_{0}$ & Eigenvalue & $\lambda_{\text {trace }}$ & $\begin{array}{c}\text { Critical } \\
\text { value of } \\
5 \%\end{array}$ & p-value \\
\hline $\mathrm{r}=0$ & 0.01137 & 16.33799 & 15.4947 & 0.0373 \\
$\mathrm{r} \leq 1$ & 0.00279 & 3.20794 & 3.8415 & 0.0733 \\
\hline
\end{tabular}

A VAR(6) model that building based on the unconstrained VAR model's optimizing lag number is as follows:

RICES_DCE $=0.7279$ PRICES_BMD.11+0.7677PRICES_DCE.11-0.5060PRICES_BMD.12 $\begin{array}{cc}(7.198) & (18.815) \\ & (-3.925)\end{array}$

$$
\begin{aligned}
& +0.2077 \text { PRICES_DCE.12-0.2434PRICES_BMD.13+0.0501PRICES_DCE.13 } \\
& (4.076) \quad(-1.869) \quad(0.971) \\
& -0.0296 \text { PRICES_BMD.14-0.0597PRICES_DCE.14+0.0141PRICES_BMD.15 } \\
& (-0.228) \quad(-1.160) \quad(0.109) \\
& +0.0282 \text { PRICES_DCE. } 15+0.0557 \text { PRICES_BMD.16-0.0035PRICES_DCE.16 } \\
& (0.554) \quad(0.542) \quad(-0.087) \\
& +18.7860 \text { const } \\
& \text { (1.031) }
\end{aligned}
$$

The $t$ value of each coefficient is shown in brackets. $\mathrm{R}^{2}$ of this model is equal to 0.9937 , and adjusted $\mathrm{R}^{2}$ is equal to 0.9936 .

Upon testing, characteristic root values of the VAR(6) model are $0.9952,0.9911,0.6665,0.6562,0.6562,0.5941$, $0.5941,0.5579,0.5579,0.4621,0.4621$ and 0.3487 . They 
all in a unit circle(see Fig .2), so VAR(6) model is a stationary system.

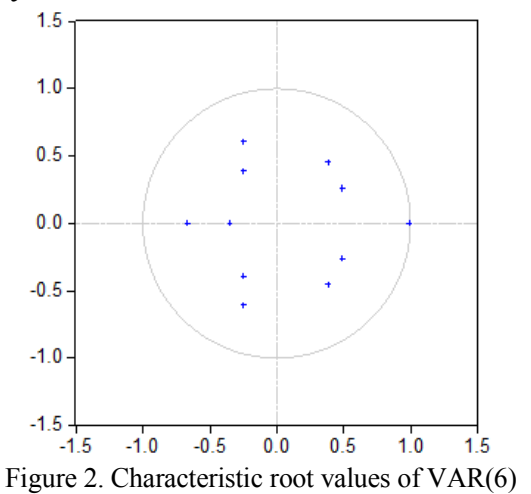

\section{E. Granger Causality Tests}

In order to test the preceding relation between PRICES BMD and PRICES DCE which contained cointegration relationship, Granger causality tests is needed. Test results are shown in TABLE IV. In the test of PRICES BMD not guides PRICES_DCE, $p$ value is equal to $0.000 \overline{0}$, rejecting null hypothesis under $1 \%$ significance level and thinking PRICES_BMD is the Granger cause of PRICES_DCE. On the contary, we can not reject null hypothesis under $1 \%$ significance level and thinking PRICES_DCE is not the Granger cause of PRICES_BMD.

TABLE IV. TEST RESULTS OF GRANGER CAUSALITY TESTS

\begin{tabular}{c|c|c}
\hline$H_{0}$ & F statistics & p-value \\
\hline $\begin{array}{c}\text { PRICES_BMD not guides } \\
\text { PRICES_DCE }\end{array}$ & 8.8781 & 0.0000 \\
$\begin{array}{c}\text { PRICES_DCE not guides } \\
\text { PRICES_BMD }\end{array}$ & 2.6262 & 0.0156 \\
\hline
\end{tabular}

\section{F. Variance Decomposition}

Variance decomposition is to analyze the impact contibution of each variable's revise update on VAR system variables. The basic idea is to devide all the endogenous variables' volatility from system according to their causes into several components, thus obtaining each imformation's relative important degree on model endogenous variables ${ }^{2}$.

To study the two markets' impact contribution to PRICES BMD and PRICES DCE, I decomposited the variance of PRICES_BMD and PRICES_DCE(see TABLE V). When lag period is 1 , the total variance of PRICES_BMD are all explained by BMD. With the increasing of lag period, variance explained by BMD slightly reducing and finally trends toward $97.1474 \%$. This implies the contribution rate that comes from BMD itself nearly occupied all the contribution rate. For PRICES_DCE, when lag period is 1, 52.6023\% of the total variance can be explained by DCE. With the increasing of lag period, variance explained by DCE gradually reducing to $23.4461 \%$, while variance explained by BMD gradually increasing to $76.5539 \%$. This implies BMD contribution a

\footnotetext{
${ }^{2}$ Fang Deng, Vector autoregression model(VAR) : VAR and its
} Eviews implementation. lot to PRICES_DCE's volatility so that it has a significant explanatory power on the influence of PRICES_DCE.

TABLE V. Results of variance decomposition

\begin{tabular}{c|c|c|c}
\hline \multirow{2}{*}{ Affected price } & \multirow{2}{*}{$\begin{array}{c}\text { Lag } \\
\text { period }\end{array}$} & \multicolumn{2}{|c}{$\begin{array}{c}\text { Influences of different } \\
\text { markets on the prices } \%)\end{array}$} \\
\cline { 3 - 4 } & 1 & 100.0000 & 0.0000 \\
& 10 & 98.6247 & 1.3753 \\
& 50 & 97.9512 & 2.0488 \\
PRICES_BMD & 100 & 97.6928 & 2.3072 \\
& 300 & 97.2608 & 2.7392 \\
& 500 & 97.1663 & 2.8337 \\
& 800 & 97.1474 & 2.8526 \\
\hline & 1 & 47.3977 & 52.6023 \\
& 10 & 63.7055 & 36.2945 \\
& 50 & 67.1725 & 32.8275 \\
PRICES_DCE & 100 & 70.2811 & 29.7189 \\
& 300 & 75.3816 & 24.6184 \\
& 500 & 76.3646 & 23.6354 \\
& 800 & 76.5539 & 23.4461 \\
\hline
\end{tabular}

\section{G. Impulse Response Function}

Impulse response function is to analyze system variables' reaction degree and duration after impacted by an endogenous variable. In this article, it is to explore the degree of affect that random errors of PRICES_BMD and PRICES_DCE after impact have to their current value and future value. Draw the impulse response function graph(see Fig .3 and Fig .4). As we can see in Fig .3, in the first day, PRICES_DCE's reaction to a new standard error information from itself is 101.0481, and then increases to 104.4408 before gradual decline; PRICES_DCE's reaction to a new standard error information from PRICES BMD is 0.0000 in the first day and soars to 22.2837 in the second day, final it presents a slowly descend tendency. PRICES BMD's reaction to new information from itself and PRICES_DCE in the first day are 29.4262 and 27.9325 respectively, then they all present a declining curve.

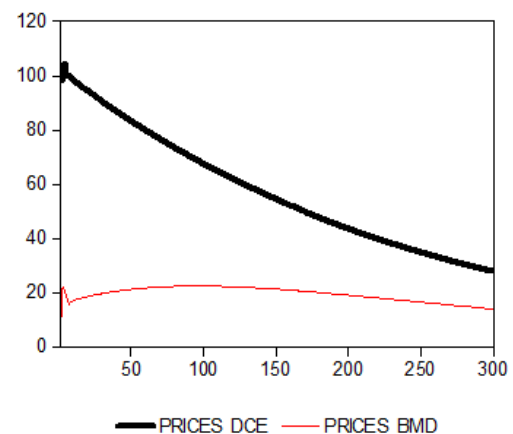

Figure 3. Impact on PRICES_DCE from the two markets 


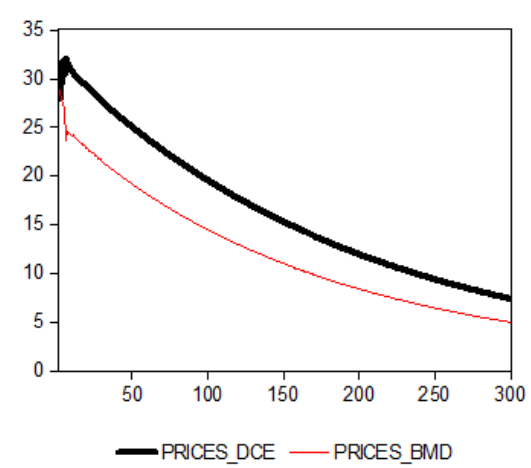

Figure 4. Impact on PRICES_BMD from the two markets

\section{CONCLUSION}

By analyzing the relationship between BMD and DCE palm oil futures prices during January 1, 2009 to December 31, 2013, this research gets the following conclusion:

1) A highly correlation exsits between BMD and DCE palm oil futures prices.

From time series plot and correlation coefficient, in between the two markets' palm oil futures prices there exist a trend similarity and correlativity obviously. The empirical study shows that PRICES_BMD time series and PRICES_DCE time series are integrated of order 1, and there exist a long-term equilibrium cointegration relationship between the two time series by Johansen cointegration test, thereby building the VAR model. In the VAR model of two markets palm oil futures prices, adjusted $\mathrm{R}^{2}$ is equal to 0.9936 . Model fitting effect is good and it passes the unit root test, so the model is a stationary system. High correlativity and tendency between BMD and DCE palm oil futures prices provide a basic condition for palm oil futures cross market arbitrage.

2) Granger causality tests further validates Malaysian has the world's palm oil fixing prices center status; Variance decomposition and impulse response function show that intertemporal arbitrage and cross matket arbitrage opportunities exist.

There is an obvious one-way causality relationship between BMD and DCE palm oil futures prices, that is, PRICES_BMD guides PRICES_DCE, and not vice versa. This implies that BMD palm oil futures prices change will necessarily impinge on DCE palm oil futures prices. In the long run, BMD and DCE palm oil prices have a cointegration relationship. In the short run, palm oil futures prices trend may appear some small deviation which provide arbitrage opportunities for hedgers and institutional investors.Although China dominates in the international palm oil consumer market, China is influenced by Malaysia a lot in fixing price of palm oil. For Malaysia, palm oil futures listed in DCE further promotes China-Malaysia trade and commerce and extends the influece of BMD in Asia main sales areas. For China, DCE palm oil futures provides the function of hedging and strengthen domestic related enterprises and individuals' ability to resist risk. In some sense, it improves Chinese right of discourse in the international palm oil trade. Malaysia as international palm oil futures fixing prices center is an economic system formed through long-term development. DCE is a "shadow market" of BMD at present. China is willing to gradually increase the influence in the international palm oil price market. This not only needs a more international futures market, but also needs to implement macro control under the market rules and build a loose development environment for the futures market.

\section{ACKNOWLEDGMENT}

I would like to express my gratitude to all those who helped me during the writing of this paper.

My deepest gratitude goes first to Professor Jianqiao Liu, my supervisor, for his patience, encouragement and professional instructions during my paper writing. Also, I would like to thank Mr Mengnan Xiao,who kindly gave me a hand when I was learning the programming.

Last but not the least, I owe much to my friends and classmates for their valuable suggestions and critiques.

\section{REFERENCES}

[1] Ke Dai, Youpeng Ke and Zhu Chen," The Analysis on the Development Trend of World Palm Oil Production and Trade," China Tropical Agriculture, vol. 36, Apr. 2010, pp.44-46.

[2] Hui Xiao, Chongfeng Wu, Jianping Bao and Zhanyu Zhu, "The Study on the Price Discovery Process of Copper between the London Mental Exchange and the Shanghai Futures Exchanges," System Sengineering-Theory Methodology Applications, vol. 13, No. 6, Dce. 2004, pp. 481-484, 489, doi: 1005-22542(2004) 060481-04.

[3] Renhai Hua and Baizhu Chen, "International Linkages of the Chinese Futures Markets," China Economic Quarterly, vol. 3, No. 3, Apr. 2004, pp. 727- 742.

[4] Xinjian Li, Chunmei Wu, Xue Min, Rui Wang and Zhenyu Yan, "Analysis on Cooperation of Soybean Oil Futures Prices, Colza Oil Futures Prices and Palm Oil Futures Prices of China," Journal of Huazhong Agricultural University( Social Sciences Edition), vol. 92, Feb. 2011, pp. 39-43, doi: 1008-3456(2011)02-0039-05.

[5] Yuezhong Li, "A Dynamic Econometric Analysis of the LME Copper Price and the SHFE Copper Price," Journal of Anhui University(Philosophy and Social Sciences), vol. 30, No. 2, Mar. 2006, pp. 132-137, doi: 1001-5019(2006) 02-0132-06.

[6] Yuduo Lu and Baichao Wang, "A Dynamic Research of Soybean Oil and Palm Oil Futures Price," Price Theory and the Practice, vol. 8, Aug. 2010, pp. 6465.

[7] Dan Wei, Xiaolong Han and Ruijin Liu, "An Empirical Research on the Relevance of International Palm Oil and Chian Vegetable Oil Market Prices," Price Theory and the Practice, vol. 12, Dec. 2012, pp. 44-45

[8] Gang Shyy and Bob Butcher, "Price Equilibrium and Transmission in a Controlled Economy:a Case Study of the Metal Exchange in Chian,” Journal of Futures Markets, vol. 8, Aug. 1994, pp. 877-890.

[9] Booth, G.G, Brockman and P..., "The Relationship between US and Canadian Wheat Futures," Applied Financial Economics, vol. 8, Aug. 1998, pp. 73-80.

[10] Thomas V. Schwarz and Andrew C. Szakmary, "Price Discovery in Petroleum Markets: Arbitrage, Cointegration, and the Time Interval of Analysis," Journal of Futures Markets, vol. 14, Apr. 1994, pp. 147-167, doi: 10.1002/fut.3990140204. 